\title{
ON AN INEQUALITY FOR THE RATIO OF GAMMA FUNCTIONS
}

\section{ANDREA LAFORGIA AND PIERPAOLO NATALINI}

Abstract. The following inequality relating to the ratio of the gamma functions

$$
\alpha \log x \leqslant x-\frac{\Gamma(x)}{\Gamma\left(x+\frac{1}{x}\right)},
$$

where $\alpha$ is a suitable constant, is established for every $x>0$. This inequality gives a contribution to the recent results, proved by several authors, involving the functions $\Gamma(x)$ and $\Gamma\left(\frac{1}{x}\right)$. It also gives an alternative proof of a conjecture formulated by D. Kershaw and recently proved by G.J.O. Jameson and T.P. Jameson [5].

Mathematics subject classification (2010): 33B15, 26D07.

Keywords and phrases: Gamma function, inequalities, ratio of gamma functions, digamma function.

\section{REFERENCES}

[1] H. Alzer, Inequalities for the gamma functions, Proc. Amer. Math. Soc., 128, (1999), 3355-3362.

[2] H. AlzER, Inequalities involving $\Gamma(x)$ and $\Gamma(1 / x)$ for the gamma functions, J. Comput. Appl. Math., 192, (2006), 460-480.

[3] W. GAUTSCHI, A harmonic mean inequality for the gamma function, SIAM J. Math. Anal., 5, (1974), $278-281$.

[4] C. Giordano, A. Laforgia, Inequalities and monotonicity properties for the gamma function, J. Comput. Appl. Math., 133, (2001), 387-396.

[5] G. J. O. JAMESON, T. P. JAMESON, An inequality for the gamma function conjectured by D. Kershaw, J. Math. Inequal., 6, no. 2, (2012), 175-181.

[6] H. H. KAIRIES, An inequality for Krull solutions of a certain difference equations, in E. F. Beckenbach, W. Walter (Eds.), ISNM General Inequalities, Vol. 3, Birkhäuser, Basel, 1983, 277-280.

[7] A. Laforgia, S. Sismondi, A geometric mean inequality for the gamma function, Boll. Un. Mat. Ital. A, 7 3, (1989), 339-342. 